Article

\title{
Association of SME and Government Policy Factors with the Creation of New Employment: Manufacturing Industry in Korea
}

\author{
Hoon Jang \\ Sejong National Research Complex, 370 Sicheng-daero, Sejong 30147, Korea; hoonjang@stepi.re.kr
}

Received: 18 May 2018; Accepted: 15 June 2018; Published: 20 June 2018

\begin{abstract}
The rise in unemployment is an important and urgent task to be tackled for the growth of economy in Korea. Although prior studies have revealed some factors leading to the creation of employment, studies simultaneously considering various factors, such as small and medium enterprises' (SMEs') basic factors, technology innovation activities, innovation capabilities, and the government policies, have been limited. This study seeks to design an integrated model that focuses on both SME and government policy factors associated with the creation of new employment. For this, we use the Korea Innovation Survey (KIS) data on 2828 firms in the manufacturing industry in Korea for 2013-2015. Using the multivariate regression model, we identified the association of SME and the government policy factors on the creation of employment. We show that sales, product innovation, organization innovation, and the support program by the government contributed to the job creation, whereas a firm's age had a negative correlation with the creation of employment. The statistical results and discussion of our findings facilitate a better understanding of the association between various SMEs' factors and the creation of employment, and therefore, should help in designing better policies and strategies for employment growth.
\end{abstract}

Keywords: SMEs; government policy; job creation; manufacturing industry; Korea

\section{Introduction}

The creation of jobs is one of the most important socioeconomic issues in the world. In particular, the creation of higher quality jobs has emerged as a key agenda in many countries, as the global economy witnesses a recessionary phase after the global economic crisis in 2008 (Organization for Economic Cooperation and Development (OECD 2011)). In general, the low economic growth leads to a loss of human resources and an increase in the cost of the social safety net, which can feed into a vicious cycle of a decline in economic growth and a rise in unemployment. In reality, according to the report from the International Labour Organization (ILO), the global economic crises in 2008 and 2011 have weakened the global employment market. It is noted that even if the economy recovers, it would be hard to cope with the demand for employment, owing to the structural weakness of the employment market (ILO 2014).

To avoid such an adverse situation, many countries have implemented policies and one of the key policies is encouraging job creation. For instance, in the case of the United States, resolving the ongoing recession and the high unemployment rate were at the top of the economy policy agenda. For this, the government submitted the American Jobs Act to aim to stimulate the economy and create qualified jobs. After the Trump Administration took office, the United States still puts the top priority for the economy growth through job creation. Specifically, they has actively promoted fiscal expansion to create jobs and prevent overseas transfer of manufacturing factories (i.e., reshoring). By doing so, they expected that nearly 25 million jobs over the next 10 years will be created (The White House 2017). 
The Europe has also continued to develop the employment strategies and the employment guidelines for each country.

As a result of these efforts, the average unemployment rate in the OECD countries has been steadily decreasing in the last five years, for which data is available and the youth employment rate has also been rising (OECD 2017). However, the case of Korea presents a different trend. The unemployment rate in Korea has been rising. More seriously, the youth unemployment rate has touched a record high. Of course, the absolute value of the unemployment rate in Korea is far below the OECD average (3.7\% versus $6.3 \%$ ). However, considering the manufacturing-industry-oriented growth, a traditional working culture (e.g., long working hours), and a lower employment rate than the other OECD countries, this situation can be interpreted as being more serious and complicated than the figures suggest.

Since the 1960s, Korea has achieved rapid growth by employing an export-driven industrialization policy. For this, the Korean government has used intensive supporting strategies for a few industries, such as those in the manufacturing sector, and by doing so, has created new jobs. In other words, Korea has been pursuing a job creation policy through export-led growth. However, after the 1997 Asian financial crisis and the 2008 global financial crisis, the economic growth of Korea has stagnated and has been adversely affected by both internal and external uncertainties. Since then, the employment condition has rapidly worsened. Indeed, until the 1980s, Korea's growth rate of employment remained high at more than 3\% per year; however, it has dropped to 1\% since the 2000s (OECD 2017).

The Korean government has recognized this as an important and urgent task and has accorded the top priority to job creation. This was also one of the economic pledges made by President Moon Jae-in who was elected in the election necessitated by the impeachment of his predecessor. Specifically, the government plans to create more than 800,000 jobs over the next five years, and to improve the overall quality of jobs by raising the minimum hourly wages and expanding employment insurance coverage. By doing so, the government drives to execute its core economic goal, that is, income-led growth (National Planning and Advisory Committee 2017).

To increase the number of new employment opportunities, small and medium enterprises (SMEs) have a fundamental role (Dana 1999; Ratten 2007). In particular, SMEs in Korea account for 99\% of Korea's total enterprises and provide $88 \%$ of the total employment. In other words, SMEs are at the center of job expansion activities in Korea. Then, how can SMEs help to expand employment? One may easily consider approaches, such as an incentive or a tax deduction scheme, if a firm hires more employees. This is one of the current policies considered by the Korean government, and some have criticized it for being very short-sighted. Instead of a "one size fits all" policy, we need to tailor policies through a deep understanding of the dynamics of SMEs and their surrounding environment. In this sense, we first understand the mechanism involving factors associated with the creation of new employment. Our study is designed to investigate the relationship between SMEs, government policies and the creation of employment. The research objective is then derived as follows:

To understand the relationships between SMEs and government policies which influence the creation of employment.

Since the early 2000s, many debates and studies have sought to explain the factors driving Korean firms' employment. They considered SMEs' basic factors, such as a firm's age and the volume of sales (Kim 2012; Kim and Bae 2005). Recently, several studies have focused on the effect of technology innovation activities on employment growth (Dachs and Peters 2014; Kwon et al. 2015). Based on the prior studies, our study is designed to provide a deeper and more comprehensive understanding of the association between SMEs-related factors and the creation of employment. Specifically, by controlling SMEs' basic factors, we investigate the effect of technology innovation activities and the government policies (supporting programs and regulations) on the growth of employment. By doing so, we aim to fill the gap in the previous literature and provide a deeper understanding of the mechanism of the job creation. 


\section{Theoretical Background}

We begin this section by reviewing the previous studies. Considering the scope of our study, we primarily focus on the following three factors: SMEs' business factors, technology innovation activities, and the government policies.

\subsection{SMEs' Basic Factors and Job Creation}

Among the many factors which can explain a firm's business situation, we review the key business factors, such as a firm's age, sales, export, and location, which may all have a close relationship with the creation of new employment.

First, we review studies on analyzing the relationship between a firm's age and job creation. According to the well-known standard economic theory by Jovanovic (1982), younger firms create more demand for employment. In line with this finding, some relevant studies have empirically demonstrated what this theory states (Earle and Telegdy 2011; Neumark et al. 2011; Haltiwanger et al. 2013; Lawless 2014). However, this does not hold for firms older than 5 years, and it is worth noting that some studies have presented a contrary result (Huber et al. 2012).

Second, we review the previous literature addressing the relationship between sales growth and employment growth. Theoretically, the creation of employment is determined by a firm's expected return from creating new jobs (Cahuc and Zylberberg 2004; Pissarides 2000); while mixed results have been reported in prior empirical studies. Chandler et al. (2009) noted that many studies and reports have interchangeably used both sales growth and employment growth to represent a firm's growth level; however, these two terms had a low or moderate correlation (Baum et al. 2001; Delmar and Wiklund 2003; Weinzimmer et al. 1998). In the case of Sweden, the correlation coefficient was only 0.09 for a sample of small firms (Delmar and Wiklund 2003).

However, there also exist studies, in which the increase in sales led to the increase of new employment. In particular, Birch et al. (1994) referred to high growth firms as "gazelles" and provided experimental results that most of the job creation is by gazelle companies. Other studies have supported this result (Storey 1994; Bangma et al. 2005; Lim 2009).

Next, we turn our attention to the studies which explained whether a firm exports new employment. In general, prior studies analyzing the relationship between an increase in exports and job creation have shown mixed results. Thus, a set of studies finds that economic development based on an increase of exports clearly leads to job creation (Bustos 2011; Ernst 2005; James and Fujita 2000; Kiyota 2014); another showed that the liberalization of trade among countries reduces the demand for labor (Greenaway et al. 1999; Leichenko 2000; Kilkenny and Partridge 2009). In other words, there may exist a positive or negative impact on new employment, depending on the difference between the market expansion effect and the labor demand shrinkage effect.

Last, we review the prior studies that analyzed how a firm's location variable affects job creation. One might easily expect that there exist spatial differences because the economic activities are unevenly distributed. Building on this idea, many studies have shown that there exists a meaningful correlation between a firm's location and job creation (Act et al. 2007; Loof and Nabavi 2013; Feser et al. 2008; Fallah et al. 2014; Kim et al. 2013).

Among the reviews about SMEs' basic factors and the creation of employment, we are particularly interested in examining the association between two basic factors (a firm's age and the sales volume) and the creation of employment. For this, based on the standard economic theories, we established hypotheses as follows:

Hypothesis 1-a. A firm's age negatively affects the creation of employment.

Hypothesis 1-b. A firm's sales volume positively affects the creation of employment. 


\subsection{Innovation Activity and Job Creation}

A firm's innovation activity refers to its mechanism for commercialization of the scientific experimental results or ideas (Scotchmer 2006; Utterback 1996). Therefore, an innovation activity is generally regarded as a key driving force in improving a firm's competitiveness, and many companies are making significant efforts to develop such a capability (Nunes and Balsa 2013; Peres et al. 2010).

Although it is difficult to derive a unifying theoretical conclusion about the impact of innovation activities on the growth of employment, we present some theoretical findings regarding the association between innovation activities and the creation of employment. Schumpeter (2017) stated that the introduction of new products from a result of technological innovation replaced existing products and led to a decrease in employment in making such products; however, it creates new employment in the sector of new products. Therefore, the creation of employment is determined by the difference between the number of jobs in old and new areas. The Real business-cycle theory and the Search theory described that innovation creates new employment. On the other hand, the new Keynesian economists suggested that employment will decline in the short term when technological innovation occurs. Neo-classical economists also stated that technological innovation will decrease the number of new jobs in the long run.

In general, there are four types of innovation activities. Among them, most prior studies have considered two innovation activities-product and process innovation. Product innovation can be defined as a means of creating demand through the emergence of new products or an improvement of existing products. In other words, a firm's product innovation can be regarded as a way of expanding its market competitiveness and market share. Theoretically, classical economists emphasized that the impact of product innovation and technological innovation leads to a large, positive employment effect. Empirically, most studies have also indicated that product innovation promotes job creation (Dachs and Peters 2014; Harrison et al. 2008; Lofsten and Lindelof 2005). It is worth noting that a new product developed through product innovation may completely replace an existing product, which could have a negative effect on employment generation.

Another major innovation activity studied in the literature is process innovation. Process innovation can be stated as an activity to improve productivity, such as introducing automation or building a system for mass production. According to the Marxist philosophy, it is impossible that labor-saving machines create a sufficient number of jobs (Wood 2004). Of course, some economic theories present the existence of indirect effects which can compensate for the reduction in employment, which is referred to as the theory of compensation. In line with this, empirical studies on the effect of process innovation on job creation have shown mixed results.

Previous studies on process innovation have shown mixed results, that is, the impact of process innovation is quite unclear. Specifically, it may have a negative impact on job creation because it reduces the effect of labor input (Lachenmaier and Rottmann 2011). On the contrary, some studies showed that process innovation positively affects job creation, especially in the long run (Hong et al. 2010). Therefore, the employment creation effect from process innovation may vary, depending on various factors, such as the demand elasticity of products, market environment, and the relationship between managers and employees (Choi et al. 2011; Hong et al. 2010).

Other innovation activities to be considered in this study are organizational innovation and marketing innovation. Organizational innovation can be defined as an innovation activity to enhance the efficiency of a business operation by introducing innovative organizational management policies, such as a flexible working time system. On the other hand, marketing innovation is generally referred to as an innovation activity which tries to increase the value of a product by improving brand communication, new market exploration, and an optimization of marketing processes (Bryson et al. 2012; Theodorakopoulos et al. 2014).

Considering that the enterprise environment is getting more complicated and diverse, organizational and marketing innovation are essential to enhance a firm's competitiveness and its survival capability. Studies have revealed that organizational innovation contributes to a firm's sustainable growth and its competitiveness (Brown and Eisenhardt 1997; Crossan and Apaydin 2010). 
It is worth noting that this type of innovation does not require many employees, and thus, it may negatively affect new employment. On the other hand, marketing innovation is known to have a positive impact on job creation (Gregory et al. 2007; Lavie 2007; Zou et al. 2003).

As noted above, it is hard to derive consistent theoretical conclusions on the relationship between innovation activities and the creation of jobs. Therefore, we built the following hypotheses by combining various theories and the results of empirical studies.

Hypothesis 2-a. Product innovation activities positively affect the creation of employment.

Hypothesis 2-b. Process innovation activities negatively affect the creation of employment.

\subsection{Government Policy and Job Creation}

The government's support and regulatory policies are generally related to job creation. In theory, government assistance and providing benefits to SME businesses can result in creating new employment (Bartik 2003; Anderberg 2006). Empirically, studies have confirmed that the government's SME support can promote SMEs' competiveness and create new employment (Park et al. 2014; Yoon et al. 2009).

On the other hand, regulatory obstacles may discourage job creation. Since the early 2000s, many studies have dealt with the relationship between regulations and labor demands (Krueger and Pischke 1998; Djankov et al. 2002). Most of them have indicated that the government's regulations did not help in job creation (Bertrand and Kramarz 2002; Ciccone and Papaioannou 2007; Yakovlev and Zhuravskaya 2007).

The reviews above state that government support programs contribute to creating new employment, while regulations impede job creation. Based on the theory of the SMEs related government support policy impact on job creation and empirical studies' results, we developed the following hypothesis:

Hypothesis 3. Government support programs positively affect the creation of employment.

\section{Research Method}

The purpose of this study is to identify the SMEs' and government policy factors that are associated with new employment. For this, we performed a retrospective study using nationwide data. Specifically, we set the annual growth rate of employees of the SMEs as a dependent variable. Fifteen explanatory variables in two sections were included: SMEs' factors and government policy factors (support and regulations). It is worth noting that SMEs' factors were divided into three sub-categories: SMEs' basic factors, innovation activities, and innovation capabilities. For the econometric analysis, we primarily used a multivariate regression model. Figure 1 shows a schematic diagram of our study.

The regression model of our study is shown in Equation (1), where empl represents a dependent variable, which is the rate of increase of created jobs during the studied period; $X_{i}$ is a vector of 15 independent variables. We assume that the error term $\varepsilon_{i}$ follows a normal distribution. $\alpha$ and $\beta$ are coefficient vectors that will be estimated through an analysis.

$$
\text { empl }=\alpha+\beta \times X_{i}+\epsilon_{i}, i=1, \ldots, 15
$$


Business Factor

- Age

- Sales

- Export sales ratio

- A firm's location

- The use of sub-contraction

- Wage rate

- Employment inducement rate

\section{Innovation activity}

- Product innovation

- Process innovation

- Organizational innovation

- Marketing innovation

\section{R\&D capability}

- R\&D Budget

- R\&D Manpower

\section{Government policy}

- SMEs' supporting program

- Regulation

Figure 1. A schematic diagram of this study. 


\subsection{Data Collection}

In this study, we used the data from the Korea Innovation Survey (KIS) of 2017. The survey is conducted by the Science and Technology Policy Institute (STEPI) in Korea. It is worth noting that the KIS started in 1996 and has been designated as government-approved statistics by the National Statistical Office in 2003. In addition, the KIS is regarded as the most important and essential statistical data to investigate innovation activities at the enterprise level. The survey was designed in accordance with the OECD Oslo manual, and therefore, it has the advantage of being comparable across countries. ${ }^{1}$

It is worth noting that we utilized data from the manufacturing industry. Since Korea is known as a manufacturing-centered country and this sector plays an important role in developing its economy ${ }^{2}$, it represents the typical industrial characteristics of Korea.

In 2017 (including histories between 2013 and 2015), the KIS included 4000 companies in the manufacturing sector, and each firm gave responses about their enterprise operations and innovation activities conducted since 2013. In our analysis, we excluded 186 companies, which were large corporations, and 986 with poor-quality responses including missing values were also ruled out. The final dataset used in our analysis included 2828 firms for our analysis. In Table 1, we presented the basic information on the dataset. Specifically, we included the size of firms [medium-sized enterprises $(1018,36.3 \%)$ and small firms $(1810,63.7 \%)]$, the firm's age (approximately 17 years), the number of employees (on average 87 persons per each firm), and the sales amount (1.884 in ten million dollars). We also showed the location of studied firms (38.7\% of them are located in metropolitan areas including Seoul). Their main markets were private $(91.7 \%)$, overseas $(5.3 \%)$, and public $(4.0 \%)$.

Table 1. Descriptive information on the dataset.

\begin{tabular}{lc}
\hline \multicolumn{1}{c}{ Variable } & Value \\
\hline Cooperative Type & \\
\hline $\begin{array}{l}\text { Medium-sized firm } \\
\text { Small firm }\end{array}$ & $1018(36.3 \%)$ \\
\hline Firm's age (average years) & $1610(63.7 \%)$ \\
\hline Number of employees (person) & 87.1 \\
\hline R\&D manpower (ratio) & $6.7 \%$ \\
\hline Sales (in ten million dollars) & 1.884 \\
\hline Exports sales ratio & $6.2 \%$ \\
\hline Location & \\
\hline Metropolitan area (including Seoul) & $1094(38.7 \%)$ \\
Others & $1734(61.3 \%)$ \\
\hline Main market & \\
\hline Public sector & $113(4.0 \%)$ \\
Private sector & $151(5.3 \%)$ \\
Overseas & $2564(91.7 \%)$ \\
\hline
\end{tabular}

The details of the variables included in our study were shown separately in Section 4.1.

1 There exists a Community Innovation Survey (CIS) from the European Union. The EU provides an analysis report based on this data set.

2 According to the report from the Bank of Korea, the contribution of the manufacturing industry to GDO (Gross Domestic Output) of Korea was calculated to be $52.2 \%$; the service industry contributed $36.5 \%$. 


\subsection{Variables and Measurements}

To measure of the effect of employment creation by SMEs in Korea, we primarily considered the ratio of the change in the number of employees during the studied period in each firm to the total number of original employees, which is calculated from the following Equation (2):

$$
\text { empl }=\left(E_{N}-E_{0}\right) / E_{0}
$$

where $E_{N}$ represents the number of employees recorded in the last year (2015) and $E_{0}$ shows the number of employees in the initial year (2013).

We now explain the covariates. Recall that SME factors are grouped into three categories-SMEs' basic factors, innovation activities, and innovation capabilities. Seven explanatory variables-age, sales, exports sales ratio, a firm's location, the use of sub-contraction, wage rate, and employment inducement ratio-were considered in the group of SMEs' basic factors. It is worth noting that three variables (sub-contraction, wage rate, and employment inducement ratio) were finally incorporated into our study based on the experts' opinion (Lee and Jang 2017). Age is a continuous-type variable and is defined as the difference between the current year (2017) and the year of the firm's establishment. The sales and exports sales ratio are also continuous-type and were calculated by using the survey data. In order to consider the geographical features of an SME, we defined the location variable, which is coded as a categorical-type variable. It takes the value 1 if a firm is located in the metropolitan area including Seoul; a value of 2 if a firm is in the urban area; and 3 is assigned if a firm is located in rural areas. Similarly, we used a binary variable named sub-contraction to represent whether a firm has used sub-contraction (1, if used; 0 otherwise) in their business. The wage rate variable represents the average wage in the sub-sector of the manufacturing industry to which a firm belongs. Finally, the employment inducement ratio, which is defined as the number of employees induced into employment when a million dollars are invested in a specific sector of the manufacturing industry, is included as a continuous-type variable and represents the unique characteristic of sub-sectors in the manufacturing industry. For this, we used the data from the Bank of Korea (Bank of Korea 2016).

Second, we considered four types of innovation activities defined in the KIS data: product, process, organizational, and marketing innovation. We set up each type of innovation activity as a binary variable. If a company performed at least one innovation activity in the last three years, we assigned value 1 , otherwise, value 0 was used.

To assess the overall capability of a firm's innovation capability, we considered two types of variables. The first is the R\&D investment to sales ratio; the other is the ratio of the number of $R \& D$ employees to the total number of employees. These are both coded as continuous-type.

Last, we included two more variables that capture the government support programs and regulations. According to the KIS data, the government support programs are classified into the eight categories, and SMEs are required to mark if they used any of the programs in each category. Similarly, the government regulations are grouped into seven categories and SMEs mark the relevant category if they have experienced any difficulties due to regulations. In our study, we calculated the ratio of the sum of marked categories for each firm to the total number of government support (or regulation) categories. Therefore, this value would be larger for companies requiring more support to overcome difficulties.

It is worth noting that the eight categories of the government support programs are: (1) research and development support; (2) support for acquisition of intellectual property; (3) commercialization support; (4) support to resolve manpower shortage; (5) support for industry-university-institute collaboration; (6) support for a regulatory reform; (7) support for the mutual growth of large firms and SMEs; and (8) support for global market development. Likewise, the seven areas of government regulation are: (1) R\&D investment; (2) new business expansion; (3) new facility establishment; (4) management flexibility; (5) distribution and sales; (6) product specification; and (7) others. It is also worth pointing out that the data were imported and analyzed by using $\mathrm{R}$. 


\section{Results}

\subsection{Descriptive Statistics}

Table 2 summarizes the descriptive statistics of the data we used. The average value of empl was $3.3 \%$ and its standard deviation was $23.4 \%$.

Table 2. Descriptive statistics of variables.

\begin{tabular}{|c|c|c|c|c|c|c|}
\hline Type & Variable (Code) & Type & Mean & Standard Deviation & Min & Max \\
\hline Dependent Variable & Employment Growth Rate (empl) & Continuous & 0.033 & 0.234 & -0.990 & 5.857 \\
\hline \multirow{10}{*}{ SME factor } & Business factor & & & & & \\
\hline & Age (age) & Continuous & 16.672 & 10.132 & 4.000 & 66.000 \\
\hline & Exports sales ratio (exp_r) & Continuous & 0.062 & 0.157 & 0.000 & 1.000 \\
\hline & Location $(l o c)$ & Categorical & 0.907 & 0.810 & 0.000 & 2.000 \\
\hline & Wage (wag)* & Continuous & 36.339 & 5.750 & 24.810 & 59.510 \\
\hline & Innovation activity & & & & & \\
\hline & Product innovation (prd_inno) & Binary & 0.312 & 0.463 & 0.000 & 1.000 \\
\hline & Process innovation (prc_inno) & Binary & 0.250 & 0.433 & 0.000 & 1.000 \\
\hline & Organizational innovation (org_inno) & Binary & 0.289 & 0.454 & 0.000 & 1.000 \\
\hline & Marketing innovation (mkt_inno) & Binary & 0.237 & 0.426 & 0.000 & 1.000 \\
\hline \multirow[t]{2}{*}{ Government policy factor } & Supports (supp) & Continuous & 0.200 & 0.292 & 0.000 & 1.000 \\
\hline & Regulations (regu) & Continuous & 0.127 & 0.256 & 0.000 & 0.875 \\
\hline
\end{tabular}

${ }^{*}$ In ten million dollars.

We now describe the 15 explanatory variables. The average value of the firm's age was found to be 16.672 years and the standard deviation was 10.131 years. The average of sales (per year) of the studied data was 1.884 (in ten million dollars) and its standard deviation was 2.507. The mean of exports sales ratio of the studied firms was $6.2 \%$ and its standard deviation was $15.7 \%$. Of the 2828 firms in our study, 37.9\% of them are located in either Seoul or metropolitan areas; while $28.6 \%$ of them are located in rural areas. Similarly, 39.7\% of the total SMEs have used sub-contraction at least once in their business operation.

Regarding innovation activities, approximately 27.2\% of the total SMEs had conducted at least one innovation activity. Product innovation was the most frequently used $(31.2 \%$ of firms) and marketing innovation $(23.8 \%)$ was the least used among the four innovation activities. It is worth noting that the average of the number of innovation activities was 1.089, which shows that SMEs in Korea did not perform multiple innovation activities.

We now turn our attention to the area of the innovation capability. On average, SMEs in Korea employed approximately $1.6 \%$ of the total number of employees, and they invested around $6.7 \%$ of their total sales value on R\&D activities.

Last, we focus on the government policy. As noted, SMEs in Korea have used support programs in approximately two out of the eight categories. They had experienced difficulties in their business due to the government regulations in one out of seven areas.

\subsection{Regression Results}

Before running a regression model, we checked the variance inflation factors (VIF) of all independent variables and confirmed that there are no significant correlations among variables $(<2.0)$. Therefore, we included all variables in our analysis.

The F-value of the regression model (3.124) and $p$-value $(p<0.001)$ verified that our multivariate regression model was statistically significant. Further, the results of the Durbin-Watson test $(p$-value $=0.621)$, the Shapiro-Wilk test ( $p$-value $=0.571)$, and the Breusch-Pagan test $(p$-value $=0.071)$ also confirmed that the 
assumptions of our regression model are valid and that the results of the regression model are reasonably interpreted to analyze the association between the dependent variable and the set of explanatory variables. The regression results are then presented in Table 3.

The results indicated that the following factors were positively associated with new employment: (1) sales ( $p$-value: 0.000); (2) product innovation ( $p$-value: 0.031); (3) organizational innovation ( $p$-value: 0.017$)$; and (4) support programs ( $p$-value: 0.016$)$. On the contrary, a firm' age ( $p$-value: 0.009$)$ negatively affects the job creation by SMEs in Korea (Model 1). In analyses using each sector's variables (Models 2 through 5), we did not find any significant differences, compared with the integrated model. However, in the analysis using the innovation activity variables, we found that organizational innovation was positively related to the employment creation, which is not significant in the integrated model (Model 3). Recall that we proposed five hypotheses: H1-a: a firm's age negatively affects the creation of employment; H1-b: a firm's sales volume positively affects the creation of employment; $\mathrm{H} 2-\mathrm{a}$ : product innovation activities positively affect the creation of employment; H2-b: process innovation activities negatively affect the creation of employment; H3: the government's support programs positively affect the creation of employment. We now have results for these hypotheses. $\mathrm{H} 1-\mathrm{a}, \mathrm{H} 1-\mathrm{b}, \mathrm{H} 2-\mathrm{a}$, and $\mathrm{H} 3$ are accepted; H2-b is rejected due to the fact that process innovation does not contribute to the creation of employment. We can now infer that sufficient statistical support exists for the validity of the arguments. 
Table 3. Regression results of the creation of employment.

\begin{tabular}{|c|c|c|c|c|c|}
\hline \multirow{2}{*}{ Variable (Code) } & Model 1 & Model 2 & Model 3 & Model 4 & Model 5 \\
\hline & Estimate ( $t$-Value) & Estimate ( $t$-Value) & Estimate ( $t$-Value) & Estimate ( $t$-Value) & Estimate ( $t$-Value) \\
\hline Intercept & $0.026(1.290)$ & $0.037(1.957) *$ & $0.019(3.284) * *$ & $0.031(5.853)^{* * *}$ & $0.023(4.170)^{* * *}$ \\
\hline \multicolumn{6}{|l|}{ Business factor } \\
\hline Age (age) & $-0.001(-2.623)^{* *}$ & $-0.001(-2.603)^{* *}$ & & & \\
\hline Sales (sales) & $0.008(3.937)^{* * *}$ & $0.009(5.136)^{* * *}$ & & & \\
\hline Exports sales ratio (exp_r) & $0.002(0.070)$ & $0.008(0.266)$ & & & \\
\hline Location $(l o c)$ & Reference & Reference & & & \\
\hline Location_urban (urb) & $-0.004(-0.388)$ & $-0.006(-0.571)$ & & & \\
\hline Location_rural (rul) & $-0.007(-0.622)$ & $-0.006(-0.584)$ & & & \\
\hline Sub-contraction (subc) & $-0.008(-0.809)$ & $-0.006(-0.691)$ & & & \\
\hline Wage (wag) & $0.000(0.032)$ & $0.000(1.081)$ & & & \\
\hline Employment inducement rate (empl_ir) & $0.001(0.032)$ & $0.001(-0.285)$ & & & \\
\hline \multicolumn{6}{|l|}{ Innovation activity } \\
\hline Product innovation (prd_inno) & $0.023(2.076) *$ & & $0.023(2.245) *$ & & \\
\hline Process innovation (prc_inno) & $-0.001(-0.062)$ & & $0.003(0.286)$ & & \\
\hline Organizational innovation (org_inno) & $0.027(2.389)^{*}$ & & $0.032(3.032)^{* *}$ & & \\
\hline Marketing innovation (mkt_inno) & $-0.022(-1.848)$ & & $-0.017(-1.433)$ & & \\
\hline \multicolumn{6}{|l|}{ Innovation capability } \\
\hline R\&D budget $\left(r n d \_b\right)$ & $-0.168(-1.429)$ & & & $0.052(1.114)$ & \\
\hline R\&D manpower (rnd_m) & $-0.023(-0.485)$ & & & $-0.128(-1.140)$ & \\
\hline \multicolumn{6}{|l|}{ Government policy } \\
\hline Support programs (supp) & $0.005(2.419) *$ & & & & $0.006(3.228)^{* *}$ \\
\hline Regulations $(r e g u)$ & $-0.002(-0.816)$ & & & & $-0.000(-0.136)$ \\
\hline R-squared (Adjusted R-squared) & $0.017(0.012)$ & $0.011(0.008)$ & $0.005(0.004)$ & $0.001(0.000)$ & $0.004(0.003)$ \\
\hline F-statistics ( $p$-value) & $3.124(0.000)^{* * *}$ & $3.931(0.000)^{* * *}$ & $4.147(0.002) * *$ & $0.959(0.383)$ & $5.704(0.003)^{* *}$ \\
\hline
\end{tabular}




\section{Discussion}

As the creation of employment has been recognized an important and urgent task for the Korean government, understanding factors associated with job creation is essential for designing evidence-based policies and programs. In this paper, we investigated the effect that several factors related to Korean SMEs have on creating employment. With the updated data from KIS 2017, we aimed to reveal the factors that affect the creation of employment. In particular, we focused on a firm's innovation activity and the surrounding environment (the government's supporting program and regulations) by controlling several SMEs' business factors. We believe that our study can contribute to the existing literature on related areas, as well as support the decision-making of industrial researchers and policymakers.

In particular, our findings have several important implications: First, a firm's age and sales have an opposite effect on the growth of employment. Age was negatively related to the increase of employees, that is, new and young firms play an important role in creating the new employment. This is consistent with the prior studies and the report from the Korean government that the employment growth rate of companies in the early stage of establishment is higher than that in the mature stage (Cho et al. 2016; Earle and Telegdy 2011; Haltiwanger et al. 2013; Lawless 2014). In addition, in the case of the U.S., firms that have been in existence for less than five years account for $20 \%$ of the gross job creation (Wiens and Jackson 2014). On the other hand, the sales variable positively affects job creation. This is consistent with some previous studies in Korea (Storey 1994; Bangma et al. 2005; Lim 2009). Moreover, based on theories from labor economics, more labor is required to produce and to sell more products.

An implication from the above experimental results is more crucial than the results presented. In particular, since the effect of job creation by young firms has been proved, the government should focus on ways to effectively nurture young firms and related ecosystems. For instance, providing a complete package of technology and financial support for innovative start-ups can be considered. Further, a policy should be framed to ensure that high-growth companies maintain their employment growth trend. In particular, there should be an alert during jobless growth, that is, when sales rise, employment falls. Fostering a service industry or promoting a technology-intensive labor market may be effective options to prevent the jobless growth.

Second, we observed that a firm engaged in product innovation and organization innovation had a positive impact on employment. This is quite plausible as the majority of prior studies have arrived at similar results (Dachs and Peters 2014; Harrison et al. 2008; Lofsten and Lindelof 2005). It is worth noting that organizational innovation does not generally require many employees and does not aim at creating new employment. However, considering the extent to which organizational innovation is included, new employment can be created through the hiring of experts in the domains of education and organization management, for the establishment of research institutes or new corporations, and for managing the changes in working policies. Therefore, the fact that organizational innovation positively affects new employment is understandable.

Third, we further investigated the government support programs that are more effective in creating more jobs. For this, we additionally executed a regression model with the eight supporting program variables. The results are shown in the supplementary section. As indicated, among supporting programs, we found that support programs of SMEs' research and development and those resolving manpower shortages were particularly helpful in promoting the growth of employment (refer to the supplementary section for more details). This provides useful information for policy makers to prioritize or re-design policies to create employment. On the other hand, despite the estimates having a negative sign, government regulation was not statistically significant in creating new employment. Even so, we would like to note that the government should design regulations carefully since many prior studies have noted that regulations generally hinder SMEs' business operations (Bertrand and Kramarz 2002; Ciccone and Papaioannou 2007; Yakovlev and Zhuravskaya 2007). 
Although we have provided insightful results, our study has several limitations. First, due to its retrospective nature, errors in data measurement or collection are possible. For instance, considering that we totally rely on the response sheet, each firm's innovation activities may not have been captured accurately. However, this is very common in observational studies and we believe that the sample size can mitigate this risk. Second, since we used data collected in Korea, it is hard to generalize it to other geographies, that is, some factors may have a different effect elsewhere, due to regional variations. Likewise, our study focused only on the manufacturing industry, and other sectors, such as the service industry, may behave in a different way. Last, since our data only contain information for the last three years, it may be insufficient to capture medium- or long-run impacts on job creation. Indeed, the effect of some factors is often delayed, and one of the promising lines of research would involve working on data that covers a longer period.

Despite these limitations, the authors believe that our analysis provides a practical and constructive approach to better understand the association between various SMEs' related factors and the creation of employment. Further, we expect that our results can help future studies and policy design initiatives to analyze and improve the government's economic development roadmap.

Funding: This research received no external funding.

Acknowledgments: The data used in this study is based on "KIS (Korea Innovation Survey) Manufacturing and Service Industry, 2017". We express our gratitude to Kang, Heejong, who pre-processed KIS data for analysis. We would also like to thank Lee, Yunjun, who studied the related project at STEPI.

Conflicts of Interest: The author declares no conflicts of interest.

\section{References}

Act, Zoltan J., Crmington Armington, and Ting Zhang. 2007. The determinants of new firm survival across regional economies: The role of human capital stock and knowledge spillover. Papers in Regional Science 86: 367-91.

Anderberg, Marc. 2006. Job chains: Theory and practical implications for workforce and economic development. In Beyond the Numbers: Labor Market Information Research and Writings. Austin: Johnson School of Public Affairs.

Bangma, K., Petra Gibcus, and Pieter Van Eck-Van der Sluijs. 2005. Firms Dynamics and Employment. Zoetermeer: EIM.

Bank of Korea. 2016. Input-Output Statistics. 2016. A Report from the Bank of Korea. Available online: http:/ / dl.bok.or.kr/search/DetailView.ax?cid=935995 (accessed on 5 December 2017).

Bartik, Timothy J. 2003. Local Economic Development Policies. Upjohn Institute Working Paper No. 03-91. Kalamazoo: W.E. Upjohn Institute for Employment Research.

Baum, J. Robert, Edwin A. Locke, and Ken G. Smith. 2001. A multidimensional model of venture growth. Academy of Management Journal 44: 292-303. [CrossRef]

Bertrand, Marianne, and Francis Kramarz. 2002. Does entry regulation hinder job creation? Evidence from the French retail industry. The Quarterly Journal of Economics 117: 1369-413. [CrossRef]

Birch, David, James Medoff, and Gazelles Medoff. 1994. Labor Markets, Employment Policy and Job Creation. Edited by Lewis C. Solmon and Alec R. Levenson. Boulder and London: Westview Press.

Brown, Shona L., and Kathleen M. Eisenhardt. 1997. The art of continuous change: Linking complexity theory and time-paced evolution in relentlessly shifting organizations. Administrative Science Quarterly 42: 1-34. [CrossRef]

Bryson, John, Luis Rubalcaba, and Patrik Strom. 2012. Services, innovation, employment and organization: Research gaps and challenges for the next decade. The Service Industries Journal 32: 641-55. [CrossRef]

Bustos, Paula. 2011. Trade liberalization, exports, and technology upgrading: Evidence on the impact of MERCOSUR on Argentinian firms. American Economic Review 101: 304-40. [CrossRef]

Cahuc, Pierre, and Andre Zylberberg. 2004. Labor Economics. Cambridge: MIT Press.

Chandler, Gaylen, Alexander McKelvie, and Per Davidsson. 2009. Asset specificity and behavioral uncertainty as moderators of the sales growth-employment relationship in emerging ventures. Journal of Business Venturing 24: 373-87. [CrossRef]

Cho, Janghee, Hyunbae Chun, Hongjun Kim, and Yoonsoo Lee. 2016. Job creation and destruction: New evidence on the role of small versus young firms in Korea. The Japanese Economic Review 68: 173-87. [CrossRef] 
Choi, Heesun, Minwoong Ji, Jjnhwan Cho, and Jungwoo Kim. 2011. Employment Performance of the Innovation-Type SMEs and the Policy Implications. A Report on Korea Institute for Industrial Economics and Trade. Available online: https:/ /library.kiet.re.kr/CORE/?moduleName=_core.KrmsSearchDetail\& control_no=37632 (accessed on 5 December 2017).

Ciccone, Antonio, and Elias Papaioannou. 2007. Red tape and delayed entry. Journal of the European Economic Association 5: 444-58. [CrossRef]

Crossan, Mary M., and Marina Apaydin. 2010. A multi-dimensional framework of organizational innovation: A systematic review of the literature. Journal of Management Studies 47: 1154-91. [CrossRef]

Dachs, Bernhard, and Bettina Peters. 2014. Innovation, employment growth, and foreign ownership of firms: A European perspective. Research Policy 43: 214-32. [CrossRef]

Dana, Leo Paul. 1999. Entrepreneurship in Pacific Asia: Past, Present, and Future, 1st ed. Singapore: World Scientific Press, $248 \mathrm{p}$.

Delmar, Frédéric, and Johan Wiklund. 2003. The Effect of the Entrepreneur's Growth Motivation on Subsequent Growth: A Longitudinal Study. Paper presented at the Academy of Management Meeting, Seattle, WA, USA, August 1-6.

Djankov, Simeon, Rafael La Porta, Florencio LopezdeSilanes, and Andrei Shleifer. 2002. The regulation of entry. Quarterly Journal of Economics 117: 1-37. [CrossRef]

Earle, John, and Almos Telegdy. 2011. Who Creates Jobs in Hungary? The Role of Entering, Existing, and Continuing Firms before and during the Crisis. Budapest Working Papers on the Labour Market. Available online: http:/ / www.econ.core.hu/file/download/bwp/bwp1108.pdf (accessed on 5 December 2017).

Ernst, Christoph. 2005. Trade Liberalization, Export Orientation and Employment in Argentina, Brazil and Mexico. Employment Strategy Papers. Geneva: International Labour Organization.

Fallah, Belal, Mark D. Patridge, and Dan S. Rickman. 2014. Geography and high tech employment growth in US countries. Journal of Economic Geography 14: 683-720. [CrossRef]

Feser, Edward, Henry Renski, and Harvey Goldstein. 2008. Clusters and economic development outcomes: An analysis of the link between clustering and industry growth. Economic Development Quarterly 22: 324-44. [CrossRef]

Greenaway, David, Robert C. Hine, and Peter Wright. 1999. An Empirical Assessment of the Impact of Trade on Employment in the United Kingdom. Research Paper. Nottingham, UK: Centre for Research on Globalization and Labour Markets, School of Economics, University of Nottingham.

Gregory, Gary, Munib Karavdic, and Shaoming Zou. 2007. The effect of E-commerce drivers on export marketing strategy. Journal of International Marketing 15: 30-57. [CrossRef]

Haltiwanger, John, Ron S. Jarmin, and Javier Miranda. 2013. Who creates jobs? Small versus large versus young. Review of Economics and Statistics 95: 347-61. [CrossRef]

Harrison, Rupert, Jordi Jaumandreu, Jacques Mairesse, and Bettina Peters. 2008. Does Innovation Stimulate Employment? A Firm-Level Analysis Using Comparable Micro-Data from Four European Countries. Available online: http:/ / www.nber.org/papers/w14216 (accessed on 5 December 2017).

Hong, Seongmin, Cheolgu Min, Kibeom Park, Hyungju Kim, Sookyung Hwang, Changgyun Chae, and Hanna Kim. 2010. How to Create More Jobs through Innovation Activities? A Report from Science and Technology Policy Institute. Available online: https:/ /www.stepi.re.kr/module/pubDownFile.jsp? categCd=A0201\&ntNo=486 (accessed on 5 December 2017).

Huber, Peter, Harald Oberhofer, and Michael Pfaffermayr. 2012. Who creates jobs? Small vs. large vs. young. The Review of Economics and Statistics 95: 347-61.

ILO. 2014. Global Employment Trends 2014-Risk of a Jobless Recovery. Available online: http://www.ilo.org/ global/research/global-reports/global-employment-trends/2014/WCMS_233953/lang--en/index.htm (accessed on 5 December 2017).

James, Willam E., and Natsuki Fujita. 2000. Employment and manufacturing exports in Indonesia: An input-output analysis. Working Paper. Kitakyushu, Japan: The International Centre for the Study of East Asian Development.

Jovanovic, Boyan. 1982. Selection and the evolution of industry. Econometrica 50: 649-70. [CrossRef]

Kilkenny, Maureen, and Mark D. Partridge. 2009. Export sectors and rural development. American Journal of Agricultural Economics 91: 910-29. [CrossRef]

Kim, Baegeun. 2012. Do technological innovations cause jobless growth? The Korean Economic Review 60: 5-54. 
Kim, Dong-One, and Johngseok Bae. 2005. Workplace innovation, employment relations and HRM: Two electronics companies in South Korea. International Journal of Human Resource Management 16: 1277-302. [CrossRef]

Kim, Junghong, Junmo Cho, Yoonsu Kim, Junki Ahn, Yoonsun Jung, and Dohee Lee. 2013. A Study on the Location and Growth Characteristics of Job Creating Gazelle Firms. A Report on Korea Institute for Industrial Economics and Trade. Available online: https://www.kdevelopedia.org/resource/view/ 04201403280131154.do\#.WiUZGnlLeUk (accessed on 5 December 2017).

Kiyota, Kozo. 2014. Exports and Employment in China, Indonesia, Japan and Korea. OECD Trade Policy Papers 166. Paris: OECD Publishing.

Krueger, Alan B., and Jorn-Steffen Pischke. 1998. Observations and Conjectures on the U.S. Employment Miracle. Paper presented at Third Public GAAC Symposium: Labor Market in the USA and Germany, January 10-11, pp. 99-126.

Kwon, Sang Jib, Eunil Park, Jay Y. Ohm, and Kyeongsik Yoo. 2015. Innovation activities and the creation of new employment: An empirical assessment of South Korea's manufacturing industry. Social Science Information 54: 354-68. [CrossRef]

Lachenmaier, Stefan, and Horst Rottmann. 2011. Effects of innovation on employment: A dynamic panel analysis. International Journal of Industrial Organization 29: 210-20. [CrossRef]

Lavie, Dovev. 2007. Alliance portfolios and firm performance: A study of value creation and appropriation in the U.S. software industry. Strategic Management Journal 28: 1187-212. [CrossRef]

Lawless, Martina. 2014. Age or size? Contributions to job creation. Small Business Economics 42: 815-30. [CrossRef]

Lee, Yoonjun, and Hoon Jang. 2017. Technology Innovation and Employment Performance of SMEs. Working Paper. Sejong, Korea: Science and Technology Policy Institute.

Leichenko, Robin M. 2000. Exports, employment, and production: A causal assessment of U.S. states and regions. Economic Geography 76: 303-25. [CrossRef]

Lim, Chaeyoon. 2009. Policy and Challenges for Promoting High Growth SMEs. A Report from Science and Technology Policy Institute. Available online: https://www.stepi.re.kr/module/publishDownFile.jsp? categCd=A0501\&ntNo=33 (accessed on 5 December 2017).

Lofsten, Hans, and Peter Lindelof. 2005. R\&D networks and product innovation patterns-Academic and non-academic new technology-based firms on Science Parks. Technovation 25: 1025-37.

Loof, Hans, and Pardis Nabavi. 2013. Learning and Productivity of Swedish Exporting Firms: The Importance of Innovation Efforts and the Geography of Innovation. Working Paper Series, Stockholm, Sweden: CESIS-Centre of Excellence for Science and Innovation Studies, Royal Institute of Technology.

National Planning and Advisory Committee. 2017. The Five-Year Policy Roadmap. A White Paper of South Korea. Available online: http:/ / www.korea.kr/common/download.do?fileId=145050042 (accessed on 5 December 2017).

Neumark, David, Brandon Wall, and Junfu Zhang. 2011. Do small businesses create more jobs? New evidence for the United States form the national establishment time series. The Review of Economics and Statistics 93: 16-29. [CrossRef]

Nunes, Alcina, and Carlos Balsa. 2013. Clustering entrepreneurship aspirations: Innovation, growth and international orientation of activities. International Journal of Innovation and Regional Development 5: 165-78. [CrossRef]

OECD. 2011. Promoting Policy Coherence for Decent Work and Full, Productive Employment. A Policy Note for the G20 Meeting. Available online: https://www.oecd.org/els/48732131.pdf (accessed on 5 December 2017).

OECD. 2017. OECD Employment Outlook 2017. Paris: OECD Publishing. Available online: https://dx.doi.org/10. 1787/empl_outlook-2017-en (accessed on 5 December 2017).

Park, Sungjae, Youngwoo Ko, Youngim Bae, and Minhong Oh. 2014. A Study on Evaluation of Employment Impact of SMEs' Innovation Project. A Report from Korea Labor Institute. Available online: https:/ /www.kli.re.kr/ downloadPblFile.do?atchmnflNo=19863 (accessed on 5 December 2017).

Peres, Reres, Eitan Muller, and Vijay Mahajan. 2010. Innovation diffusion and new product growth models: A critical review and research directions. International Journal of Research in Marketing 27: 91-106. [CrossRef]

Pissarides, Christoper A. 2000. Equilibrium Unemployment Theory, 2nd ed. Cambridge: MIT Press.

Ratten, Vanessa. 2007. Asian models of entrepreneurship: From the Indian union and the Kingdom of Nepal to the Japanese archipelago: Context, policy \& practice. Small Business Economics 28: 105-7.

Schumpeter, Joseph A. 2017. The Theory of Economic Development. New York: Routledge. 
Scotchmer, Suzanne. 2006. Innovation and Incentives. Cambridge: MIT Press.

Storey, David. 1994. New firms growth and bank financing. Small Business Economics 6: 139-50. [CrossRef]

The White House. 2017. Bridging Back Jobs and Growth. Available online: https://www.whitehouse.gov/ bringing-back-jobs-and-growth (accessed on 5 December 2017).

Theodorakopoulos, Nicholas, David Bennett, and Deycy Janeth Preciadoc. 2014. Intermediation for technology diffusion and user innovation in a developing rural economy: A social learning perspective. Entrepreneurship \& Regional Development: An International Journal 26: 645-62.

Utterback, Jamas M. 1996. Mastering the Dynamics of Innovation. Cambridge: Harvard Business School Press.

Weinzimmer, Laurence G., Paul C. Nystrom, and Sarah J. Freeman. 1998. Measuring organizational growth: Issues, consequences and guidelines. Journal of Management 24: 235-62. [CrossRef]

Wiens, Jason, and Chris Jackson. 2014. The Importance of Young Firms for Economic Growth. Entrepreneurship Policy Digest Kauffman Foundation. Kansas City: Kauffman Foundation.

Wood, John. 2004. Karl Marx's Economics: Critical Assessment. London and New York: Routledge, vol. 4.

Yakovlev, Evgeny, and Ekaterina Zhuravskaya. 2007. Deregulation of Business. Working Paper. Moscow: Centre for Economic and Financial Research at New Economic School.

Yoon, Yoongyu, Byunghun Lee, Pilgyu Baek, and Woonsun Hong. 2009. Analysis of Employment effect of SME Support Policy. A Report from Korea Labor Institute. Available online: https://www.kli.re.kr/kli/ rsrchReprtView.do?key=12\&pblctListNo=6732 (accessed on 5 December 2017).

Zou, Shaoming, Eric Fang, and Shuming Zhao. 2003. The effect of export marketing capabilities on export performance: An investigation of Chinese exporters. Journal of International Marketing 11: 32-55. [CrossRef]

(C) 2018 by the author. Licensee MDPI, Basel, Switzerland. This article is an open access article distributed under the terms and conditions of the Creative Commons Attribution (CC BY) license (http:// creativecommons.org/licenses/by/4.0/). 